\title{
Protein chips for detection of mite allergens using Kunitz- type protease inhibitors
}

\begin{tabular}{|c|c|}
\hline Journal: & Biotechnology Journal \\
\hline Manuscript ID: & biot.201000064.R2 \\
\hline Wiley - Manuscript type: & Short Communication \\
\hline $\begin{array}{r}\text { Date Submitted by the } \\
\text { Author: }\end{array}$ & 20-Apr-2010 \\
\hline Complete List of Authors: & $\begin{array}{l}\text { Poltronieri, Palmiro; ISPA-CNR of Italy, Institute of Sciences of Food } \\
\text { Productions } \\
\text { Cimaglia, Fabio; CNR-ISPA, Biotechnology } \\
\text { Santino, Angelo; CNR-ISPA, Plant Genetics } \\
\text { De Blasi, Marialuce; CNR-ISPA, Biotechnology } \\
\text { Krizkova-Kudlikova, Iva; VURV, immunology } \\
\text { Liu, Shaoyang; Auburn University, Biosystems engineering } \\
\text { Wang, Yuhong; Auburn University, Food Technology } \\
\text { Wang, Yifen; Auburn University, Biosystems engineering }\end{array}$ \\
\hline Primary Keywords: & Biosensors \\
\hline Secondary Keywords: & Biochemistry \\
\hline Keywords: & protein chips, protease, protease inhibitor \\
\hline
\end{tabular}

\section{s) ScholaroNE \\ Manuscript Central}




\section{Short communication ((3299 words)) \\ Protein chips for detection of mite allergens using Kunitz-type protease inhibitors. \\ Poltronieri Palmiro $^{[\mathrm{a}]} *$, Cimaglia Fabio ${ }^{[\mathrm{a}]}$, Santino Angelo ${ }^{[\mathrm{a}]}$, Marialuce Daniela De Blasi ${ }^{[\mathrm{a}]}$, Iva \\ Krizkova-Kudlikova $^{[\mathrm{b}]}$, Shaoyang Liu ${ }^{[\mathrm{c}]}$, Yuhong Wang ${ }^{[\mathrm{d}]}$, and Yifen Wang ${ }^{[\mathrm{c}]}$}

a- CNR-ISPA section in Lecce, Italy

b- RICP, VURV, Crop Research Institute, Prague, Czech Republic

c- Department of Biosystems Engineering, Auburn University, AL, USA

d- Department of Nutrition and Food Sciences, Auburn University, AL, USA

*Corresponding Author

Palmiro Poltroneri, CNR-ISPA, via Monteroni km 7, 73100 Lecce, Italy

Tel. +390832422609. Fax +390832422620

Keywords: protease, protease inhibitor, protein chips

Abbreviations: Kunitz-type protease inhibitor (KPI); Soybean Bowman-Birk protease inhibitor (S$\mathrm{BBI})$. 


\section{Introduction}

Kunitz-type protease inhibitors (KPIs), with size 22-24 kDa, are a class of plant protease inhibitors that play an important role in plant defence against pathogens and insects [1]. The Kunitztype inhibitors found in potato and other Solanum species are divided into three homology groups, A, B and C. KPI-A group includes inhibitors of aspartic proteases such as cathepsin D [2, 3]. Group KPI-B contains inhibitors of serine proteases [2, 3], e.g., trypsin and chymotrypsin. KPI-C group includes inhibitors of plant cysteine proteases as well as some non-protease hydrolytic enzymes such as $\alpha$-amylase [4].

In a previous work, we characterized the inhibitory activity of KPI group B proteins [3]. KPI-B1 and B4 were the most active inhibitors of trypsin at nanomolar concentration $(84.8 \mathrm{nM}$ for B4 and 345.5 $\mathrm{nM}$ for KPI-B1). Recombinant KPI-B proteins were tested on a panel of model proteases isolated from vertebrates, invertebrates and fungi. The assays revealed that the protease inhibitory activity is not only limited to bovine trypsin but also to red king crab (Paralithodes camtschaticus) trypsin which is structurally close to trypsin from beetle and butterfly larvae (data not shown). Thus, KPI groups contain protease inhibitors with large feasibility to trypsins from different origins.

In the present work, recombinant KPI-B1 and B4 were tested together with a known protease inhibitor in a protein chip to study the interaction with trypsin, and, together with two KPIs of group A, the interaction with three different proteases. 
Mites and beetles are often found in contaminated stored products and farming environments. The contamination of stored food by arthropods may seriously endanger human health [5], as they can cause allergies [6-8] and serve as vectors of fungal allergens and mycotoxins producing fungi [9]. More than twenty classes of major allergens are caused by house dust or stored product mites (Table 1). Six of these allergens are proteases and related hydrolytic enzymes [5-8]. Mites and beetles contain digestive enzymes including serine-type proteases (chymotrypsin, trypsin and a collagenolytic protease), a cysteine protease and an aspartic protease, and different proteases are abundantly present in mites' faeces.

Diagnostic tests have been developed with fixed antibodies on strips or microplates as capture probes to detect allergens, i.e., using trypsin to detect soybean allergens as STI, a marker of the presence of soybean contaminants in food [10, 11]. The KPI chips were tested in the detection of mite proteins supposed to be proteases. Protein visualization anti-mite antibodies allows relative quantification of mite proteases bound to each KPI group in each individual experiment, but is not feasible for comparison between different experiments, due to the laser scanner used.

The ultimate goal is the application of KPI proteins in the detection of mite hazards. The miniaturization of these assays will enable the creation of high-throughput tools and new diagnostics.

\section{Materials and Methods}

\subsection{Proteins used in this work}

Recombinant protein production and purification were carried out as previously described [3] and checked by western blot using a polyclonal antibody against a potato KPI-B10 protein (kindly provided by Dr. A. Shevelev). Four His-tagged KPIs, two of group B, KPI-B1 (AY945740) and KPI-B4 (AY945743), and two of group A, KPI-A1 (FJ969213) and KPI-A2 (FJ969214), were produced and used for subsequent biotechnological characterizations. Proteases (trypsin, chymotrypsin and cathepsin B), the protein controls and reagents were from Sigma (Sigma-Aldrich, Milwaukee, WI, USA).

\subsection{Protein chip preparation}

All recombinant protease inhibitors were desalted with Zeba desalt spin columns (Pierce, Rockford, IL, USA). The Kunitz-type protease inhibitors and the positive control, soybean Bowman-Birk inhibitor, were prepared at different concentrations $(0.1,0.2$, and $0.4 \mathrm{mg} / \mathrm{ml})$ in a $\mathrm{NaHCO}_{3}$ buffer (0.1 M, pH 9) with glycerol (40\% w/v) and arrayed on epoxysilane-coated Nexterion slides (Schott, 
Jena, Germany) with a robotic printing SpotArray 24 system (Perkin Elmer, Waltham, MA, USA). The SpotArray 24 was employed to print in the miniaturized protein chips. Each spot printed with SpotArray 24 contained 50-70 $\mathrm{nl}$ of $0.1,0.2$ and $0.4 \mathrm{ng} / \mathrm{nl} \mathrm{KPI}$. The printing was performed in triplicate for each protein at $4^{\circ} \mathrm{C}$ and about $60 \%$ humidity using to the SpotArray humidity control. The printed slides were incubated at room temperature for two hours at $60 \%$ humidity in a dark room to allow the reaction between epoxy groups and water. Then, the printed slides were kept dried in the dark for later use, or immediately used. The protein chips ready for use were incubated for one hour on a shaker at room temperature in a phosphate-buffered saline (PBS) containing glycine $(0.5 \mathrm{M})$ and bovine serum albumin $(\mathrm{BSA} ; 1 \% \mathrm{w} / \mathrm{v})$ to block non-specific binding. After that, the slides were washed with PBS + BSA $(0.1 \% \mathrm{w} / \mathrm{v})$ and dried in a centrifuge at $500 \mathrm{~g} \mathrm{x} 2 \mathrm{~min}$.

\subsection{Protein chip assays}

Each protease (trypsin, chymotrypsin and cathepsin B) was labelled with an Alexa-555 protein labelling kit (Molecular Probes, Life Technologies, Carlsbad, CA, USA) and purified with gel-filtration biogel P-6 (Bio-Rad, Hercules, CA, USA) to remove free dye according to the manufacturer's protocols. The probe was then applied as follows: $50 \mu 1$ of labelled, purified protease $(1 \mathrm{mg} / \mathrm{ml}$ of trypsin and chymotrypsin in Tris-hydroxymethylamonomethane (TRIS) buffer $0.1 \mathrm{M}, \mathrm{pH} 7.5$; and $1 \mathrm{mg} / \mathrm{ml}$ cathepsin B dissolved in phosphate buffer $0.1 \mathrm{M}, \mathrm{pH}$ 6.5) was applied with the hybridization buffer onto the slide, using the coverslip method [12-14] and incubated for one hour in the dark at room temperature in a humidity chamber (70\% humidity). After incubation, the slides were washed with PBS containing Tween-20 (0.2\% w/v) and BSA $(0.1 \% \mathrm{w} / \mathrm{v})$ for 15 minutes on a shaker at $4^{\circ} \mathrm{C}$. Next, the slides were washed twice with PBS + BSA $(0.05 \% \mathrm{w} / \mathrm{v})$ for five minutes on a shaker at $4^{\circ} \mathrm{C}$ and dried in a centrifuge at $500 \mathrm{~g}$ x $2 \mathrm{~min}$. Then, the slide was scanned with a Laser Scanner 428 (Affymetrix, CA, USA).

In the detection of mite extracts, protease inhibitors (KPI-A1, KPI-A2, KPI-B1, KPI-B4 and S-BBI) were spotted on slides at serial dilutions, $0.1,0.2$ and $0.4 \mathrm{ng} / \mathrm{nl}$ using the manual MicroCaster (Whatman, Brentford, UK) producing spots with greater size, around $500 \mathrm{nl}$. After protein immobilisation and slide desiccation, the chips were used the following day.

\subsection{Preparation of mite/insect allergenic proteases and detection on the protease inhibitor chip}


Mite cultures (Acarus siro, Aleuroglyphus ovatus, Lepidoglyphus destructor, Tyrophagus putrescentiae), and red flour beetle (Tribolium castaneum) culture and rabbit immunization for producing polyclonal antibodies were carried out at VURV in Prague. Protein extracts of frozen adults were obtained from starved, washed mites. Frozen adults were weighed and homogenised in phosphate buffer saline (PBS, $20 \mathrm{mM} \mathrm{Na} 2 \mathrm{HPO}_{4}, 20 \mathrm{mM} \mathrm{NaH} \mathrm{PO}_{4}, 150 \mathrm{mM} \mathrm{NaCl}, \mathrm{pH} 7$ ) and $0.1 \%$ Triton X-100. A protein concentration was determined using the Bradford method (Bio-Rad, USA). Protein concentrations were: A. ovatus extract, 3,5 $\mu \mathrm{g} / \mu \mathrm{l} ;$ A. siro extract, 2,9 $\mu \mathrm{g} / \mu \mathrm{l} ;$ L. destructor extract, $3.2 \mu \mathrm{g} / \mu \mathrm{l} ; T$. putrescentiae extract, $2,8 \mu \mathrm{g} / \mu \mathrm{l}$; and $T$. castaneum extract, $2 \mu \mathrm{g} / \mu \mathrm{l}$. The protein extract $(2-2.5 \mu \mathrm{g} / \mu \mathrm{l})$ was diluted with PBS. Twenty $\mu 1$ of hybridization solution, containing one $\mu \mathrm{l}$ of 1:10 dilution, was used, so that final concentration of proteins was between 0.2 and 0.3 $\mu \mathrm{g} / \mu \mathrm{l}$. The slides were hybridised under dark, at room temperature on a microplate shaker, then washed with TRIS buffer saline $\mathrm{pH} 7.5$ plus $0.1 \%$ Tween-20 (TBS-T). To visualize protease inhibitor-mite protein interactions, the chips were incubated with species-specific polyclonal antibodies, diluted 1:20 (1 $\mu \mathrm{g} / \mathrm{ml})$. After removal of aspecific interactions with TBS-T washes, the slides were incubated with Alexa-555-labelled protein A for the antibody detection (Figure 3). Slides were analysed with a 428 Laser Scanner (Affymetrix, USA), and images were visualised with ScanAnalyse. The sensitivity of antigen detection on protein chips was compared to results obtained using dot blot and sandwitch ELISA assays probed with the same polyclonal antibodies [15-17].

\section{Results and discussion}

\subsection{Characterization of the protein chip}

Protein chips were tested comparing trypsin binding to S-BBI, KPI-B1 and KPI-B4 recombinant proteins [4] in order to verify their performance in conditions of limited movement and orientation constrains (figure 1), Miniaturization of the protein chip was achieved using a robotic spot-arrayer, depositing $70 \mathrm{nl}$ volumes on the glass. KPI-B1 and B4 at serial dilutions showed affinity for trypsin $(10 \mathrm{ng} / \mu \mathrm{l})$ even at $0.1 \mathrm{ng} / \mathrm{nl}$ (Figure 1). High KPI-B1 sensitivity for trypsin was put in relation to a higher stability/freedom of movement of KPI-B1 bound to the glass as compared to KPI-B4, since KPI-B1 Ki is higher (345.5 for KPI-B1 and 84.8 for KPI-B4). This result shows the feasibility of KPI-B1 use in biotechnological applications.

The stability of KPI protein chips was investigated. A set of printed slides was stored for one month at $4^{\circ} \mathrm{C}$ and their performance was tested. No evident differences were detected 
compared to a freshly-printed chip. KPI proteinase inhibitors were stable for a long time without loss of activity.

\subsection{Differential KPI binding and protease specificity}

KPI-B1 and KPI-B4, together with two other Kunitz-type protease inhibitors (KPI-A1 and A2) were used on KPI protein chips to investigate different binding specificity of trypsin, chymotrypsin and cathepsin B (Figure 2A, B, and C). The protein chips showed that KPI-B1, KPIB4 and S-BBI as positive control (Figure 2A) were good binding partners for trypsin, while KPI-A1 partially interacted with trypsin. The analysis of chymotrypsin binding (Figure 2B) showed fluorescent signals only for serine protease inhibitors, KPI-B1 and KPI-B4 (as previously described using in vitro assay) [4], and S-BBI. The cathepsin-B analysis (Fig. 2C) indicated that recombinant KPI-A1 partially bound to cathepsin B, while Lactoferrin, with an affinity for cathepsin B, shows the strongest fluorescence signal.

\subsection{Anti-mite protein chips. Detection of mite allergen candidate proteins}

In this work the application of KPIs to detect mite [15, 16] or insect [17] proteases as potential allergens $[18,19]$ was proposed. Protein chips were used for capturing mite candidate proteases, detected with polyclonal antibodies specific to mite species [15-17] i.e. A. ovatus, A. siro, L. destructor, T. putrescentiae and T. castaneum, respectively (figures 3A, 3B, 3C, 3D, 3E). Optimum resolution shown in figure 3 was achieved with 1:10 extract dilution, corresponding to $0.2 \mu \mathrm{g}$ of total proteins, but positive results were obtained even with extract dilutions as low as 1:20 (corresponding to $100 \mathrm{ng}$ of total proteins, not shown). Faint signals present in positive control might have been caused either by the manual spotting or by very low amounts of trypsin-like proteases in the sample. Possible errors in the transfer of the samples from the microplates to the glass slide could be overcome using the Robotic SpotArray. Total protein extracts $(1.5 \mathrm{mg} / \mathrm{ml})$ did not produce good signals, probably due to the presence of lipids, polysaccharides and chitins that may block the protein interactions on the chip.

In the protein chip method, the sensitivity of the assay was higher, compared to the currently used sandwich-ELISA method [15]. The detection limit of the protein chip method was $0,1 \mu \mathrm{g}$ of total mite extract, while the detection limit for sandwitch ELISA method is $1 \mu \mathrm{g}$ of mite proteins using $1 \mathrm{ml}$ solutions. An advantage of the proposed method is the limited hybridisation volume with lower amounts of proteins, due to the very small surface of protein chips. However, considering that 


\section{Concluding Remarks}

In this work, the protein chip was used to detect mite proteins. Using this tool, KPI-B1 and B4 were capable of screening mite proteases that could represent potential allergens. Presently protein chips are produced only for the determination of reactivity of IgEs toward known antigens and allergens. The development of KPI chips and assays in solution as lateral flow tests (LFT) will allow the detection of mite contamination in stored food products and in environment. 


\section{Acknowledgements}

The authors thank Dr. Alexei Shevelev for providing the anti-KPI antibodies and Dr. Oscar Fernando D'Urso for technical assistance. The part of study done in RICP, Prague was supported by the project of The Czech Ministry of Agriculture, No. 0002700604.

"The authors have declared no conflict of interest."

\section{References}

[1] Valueva, T. A., Mosolov, V. V., Role of inhibitors of proteolytic enzymes in plant defence against phytopathogenic microorganisms. Biochemistry (Mosc.) 2004, 69, 1305-1309.

[2] Heibges, A., Salamini, F., Gebhardt, C., Functional comparison of homologous members of three groups of Kunitz-type enzyme inhibitors from potato tubers (Solanum tuberosum L). Mol. Gen. Genomics 2003, 269, 1215-1221.

[3] Speransky, A.S., Cimaglia, F., Krinitsina, A.A., Poltronieri, P. et al., Kunitz-type protease inhibitors group B from Solanum palustre. Biotechnol. J. 2007, 2, 1417-1424.

[4] Rawlings, N.D., Tolle, D.P., Barrett, A.J. Evolutionary families of peptidase inhibitors. Biochem. J. 2004, 378, 705-716

[5] Stejskal, V., Hubert, J., Risk of occupational allergy to stored grain arthropods and false pestrisk perception in Czech grain stores. Ann. Agric. Environ. Med. 2008, 15, 29-35.

[6] Stewart, G.A., Lake, F.R, Thompson, P.J., Faecally derived hydrolytic enzymes from Dermatophagoides pteronyssinus: physicochemical characterization of potential allergens. Int. Arch. Allergy Appl. Immunol. 1991, 95, 248-256.

[7] Shakib, F., Gough, L., The proteolytic activity of Der p 1 selectively enhances IgE synthesis: a link between allergenicity and cysteine protease activity. Clin. Exp. Allergy 2000, 30, 751-752.

[8] Stewart, G.A., Robinson, C., The immunobiology of allergenic peptidases. Clin. Exp. Allergy 2003, 33, 3-6.

[9] Hubert, J., Stejskal, V., Kubátová, A., Munzbergová, Z. et al., Mites as selective fungal carriers in stored grain habitats. Exp. Appl. Acarol. 2003, 29, 69-87.

[10] van Amerongen, A., Ostrafe, V., Gruppen, H., Meerdink, G. et al., Specific immuno(chymo)trypsin inhibitor assays for determination of (residual) activity of Bowman-Birk or Kunitz soybean trypsin inhibitors. In: Jansman G.D., Hill, J., Huisman J., van der Poel, A.F.B. (Eds.), Recent advances of research in antinutritional factors in legume seeds and rapeseed. Wageningen Pers, Wageningen, 1998, pp. 32-37. 
[11] van Amerongen, A., Wichers, J.H., Berendsen, L.B., Timmermans, A.J. et al., Colloidal carbon particles as a new label for rapid immunochemical test methods: quantitative computer image analysis of results. J. Biotechnol. 1993, 30, 185-195.

[12] Haab, B.B., Dunham, M.J., Brown, P.O., Protein microarrays for highly parallel detection and quantitation of specific proteins and antibodies in complex solutions. Genome Biol. 2001, 2, Research0004.1-0004.13.

[13] Templin, M.F., Stoll, D., Schwenk, J.M., Pötz, O., et al., Protein microarrays: Promising tools for proteomic research. Proteomics 2003, 3, 2155-2166.

[14] Cretich, M., Damin, F., Pirri, G., Chiari, M., Protein and peptide arrays: recent trends and new directions. Biomol. Eng. 2006, 23, 77-88.

[15] Krizkova-Kudlikova, I., Stejskal, V., Hubert J., Comparison of detection methods for Acarus siro (Acari: Acaridida: Acarididae) contamination in grain. J Econ Entomol. 2007, 100, 1928-1937.

[16] Kudlikova, I., Stejskal, V., Hyblova, J., Chalupnikova, J., et al., Polyclonal antibodies for detection of flour mite Acarus siro (Acari: Acaridida). Phytophaga 2004, 14, 711-720.

[17] Krizkova-Kudlikova, I., Hubert. J., Development of polyclonal antibodies for the detection of Tribolium castaneum contamination in wheat grain. J Agric Food Chem. 2008, 56, 8035-8040.

[18] Erban, T., Hubert, J., Comparative Analyses of Proteases in Seven Species of Synanthropic Acaridid Mites. Arch. Insect Biochem. Physiol. 2010 (in press).

[19] Erban, T., Erbanova, M., Nesvorna, M., Hubert, J., The importance of starch and sucrose digestion in nutritive biology of synanthropic acaridid mites: amylases and glucosidases are suitable targets for inhibitor-based strategies of mite control. Arch. Insect Biochem. Physiol. 2009, 71, 139158.

[20] Tong, J.C., Lim, S.J., Muh, H.C., et al., Allergen Atlas: a comprehensive knowledge center and analysis resource for allergen information. Bioinformatics 2009, 25, 979-980.

[21] Mari, A., Rasi, C., Palazzo, P., Scala, E., Allergen databases: current status and perspectives. Curr. Allergy Asthma Rep. 2009, 9, 376-383. 


\section{Figure captions}

Figure 1. Miniaturized protein chips in detection of fluorescent trypsin. Upper lane: KPI-B1 (left), KPI-B4 (right). Lower lane: BSA, S-BBI. 
Figure 2. Detection of three fluorescent proteases on KPI chips. Protein concentrations: 0.1, 0.2 and $0.4 \mathrm{ng} / \mathrm{nl}$ (left to right).

2-A. Selective binding of trypsin.

2-B. Selective binding of Chymotrypsin

2-C. Selective binding of cathepsin B

2-D. A scheme of spotted proteins. Upper lane: KPI-A1, KPI-A2 and KPI-B1

Lower lane: negative control (BSA), KPI-B4, positive control (S-BBI in 2A, 2B; Lactoferrin in 2C) 
Figure 3.

Detection of mite proteases using KPI chips.

3A. Detection of Aleuroglyphus ovatus using anti-A. ovatus antibodies

3B. Detection of Acarus siro using anti-A. siro antibodies

3C. Detection of Lepidoglyphus destructor using anti-L. destructor antibodies

3D. Detection of Tyrophagus putrescentiae using anti-T. putrescentiae antibodies

3E. Detection of Tribolium castaneum. using anti-T. castaneum antibodies

3F Scheme of protein spots $(0,4 \mathrm{ng} / \mathrm{nl}$, upper lane; $0,2 \mathrm{ng} / \mathrm{nl}$, middle lane; $0,1 \mathrm{ng} / \mathrm{nl}$, lower lane). 
Table 1: The major allergen classes in house dust mites and storage product mites $[20,21]$ according to websites and to the International Union of Immunological Societies' (IUIS) rules for allergen nomenclatures.

Legends: ??? unknown function

$+\quad$ suggested allergens according to their amino acid sequences and homology to known allergens

- enzymatic activity proved

\begin{tabular}{|c|c|c|c|c|c|c|c|c|c|}
\hline \multirow{3}{*}{$\begin{array}{l}\frac{v}{0} \\
\frac{\sigma}{v}\end{array}$} & \multirow{2}{*}{ Biochemical function } & \multicolumn{3}{|c|}{ Stored product species } & \multirow[b]{2}{*}{ Tyrophagus } & \multirow[b]{2}{*}{ Aleuroglyphus } & \multicolumn{2}{|c|}{ Dust species } & \multirow[b]{2}{*}{ Derrmatoph. } \\
\hline & & Acarus & Glyciphagus & Lepidoglyphus & & & Blomia & Dermatoph. & \\
\hline & & siro & domesticus & destructor & putrescentiae & ovatus & Tropicalis & farinae & Pteronyssinus \\
\hline 1 & Cysteine protease & & & 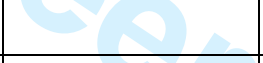 & + & + & Blo t 1 & Der f 1 & Der $\mathrm{p} 1$ \\
\hline 2 & NPC2 family & & Gly d 2 & Lep d 2 & Tyr p 2 & & Blo t 2 & Der f 2 & Der p 2 \\
\hline 3 & Trypsin & + & & + & + & + & Blo t 3 & Der f 3 & Der $\mathrm{p} 3$ \\
\hline 4 & A-amylase & $\bullet$ & & - & • & - & Blo t 4 & $\bullet$ & Der $\mathrm{p} 4$ \\
\hline 7 & $? ? ?$ & & & Lep d 7 & & 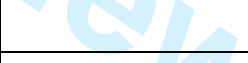 & & Der f 7 & Der $\mathrm{p} 7$ \\
\hline 8 & Glutathione S-transferase & & & & & & & & Der p 8 \\
\hline 9 & Collagenolytic serine prot. & $\bullet$ & & $\bullet$ & $\bullet$ & $\bullet$ & & $\bullet$ & Der p 9 \\
\hline 10 & Tropomyosin & & & Lep d 10 & Tyr $\mathrm{p} 10$ & & Blo t 10 & Der f 10 & Der $\mathrm{p} 10$ \\
\hline 11 & Paramyosin & & & & & & Blo t 11 & Der f 11 & Der $\mathrm{p} 11$ \\
\hline 16 & Gelsolin/villin & & & & & & & Der f 16 & \\
\hline 17 & Ca binding protein & & & & & & & Der f 17 & \\
\hline
\end{tabular}




\begin{tabular}{|c|c|c|c|c|c|}
\hline 18 & Chitinase & & & Der f 18 & \\
\hline 19 & Anti-microbial peptide & & Blo t 19 & & \\
\hline 20 & Arginine kinase & & & & Der $\mathrm{p} 20$ \\
\hline 21 & $? ? ?$ & & Blo t 21 & & Der $\mathrm{p} 21$ \\
\hline 22 & $? ? ?$ & & & Der f 22 & \\
\hline 23 & $? ? ?$ & & & & Der $\mathrm{p} 23$ \\
\hline 24 & Troponin C & Tyr p 24 & & & \\
\hline
\end{tabular}




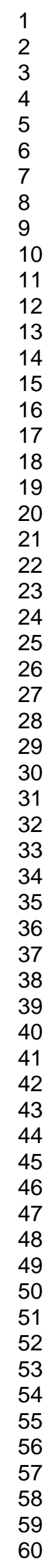

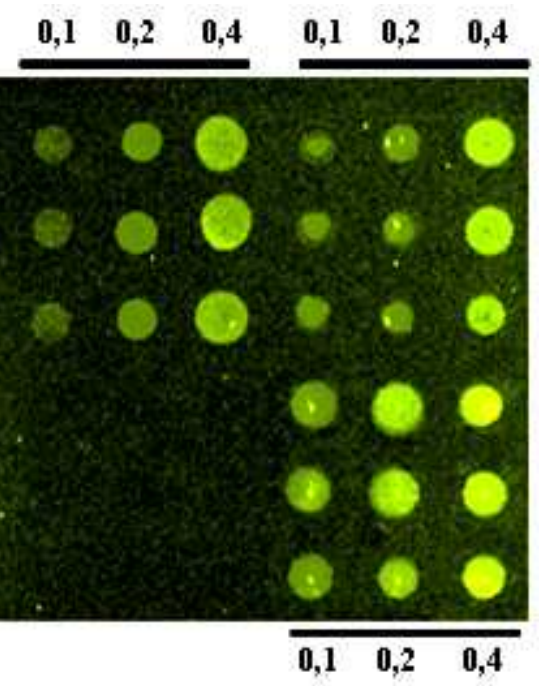

$77 \times 98 \mathrm{~mm}(68 \times 68 \mathrm{DPI})$ 


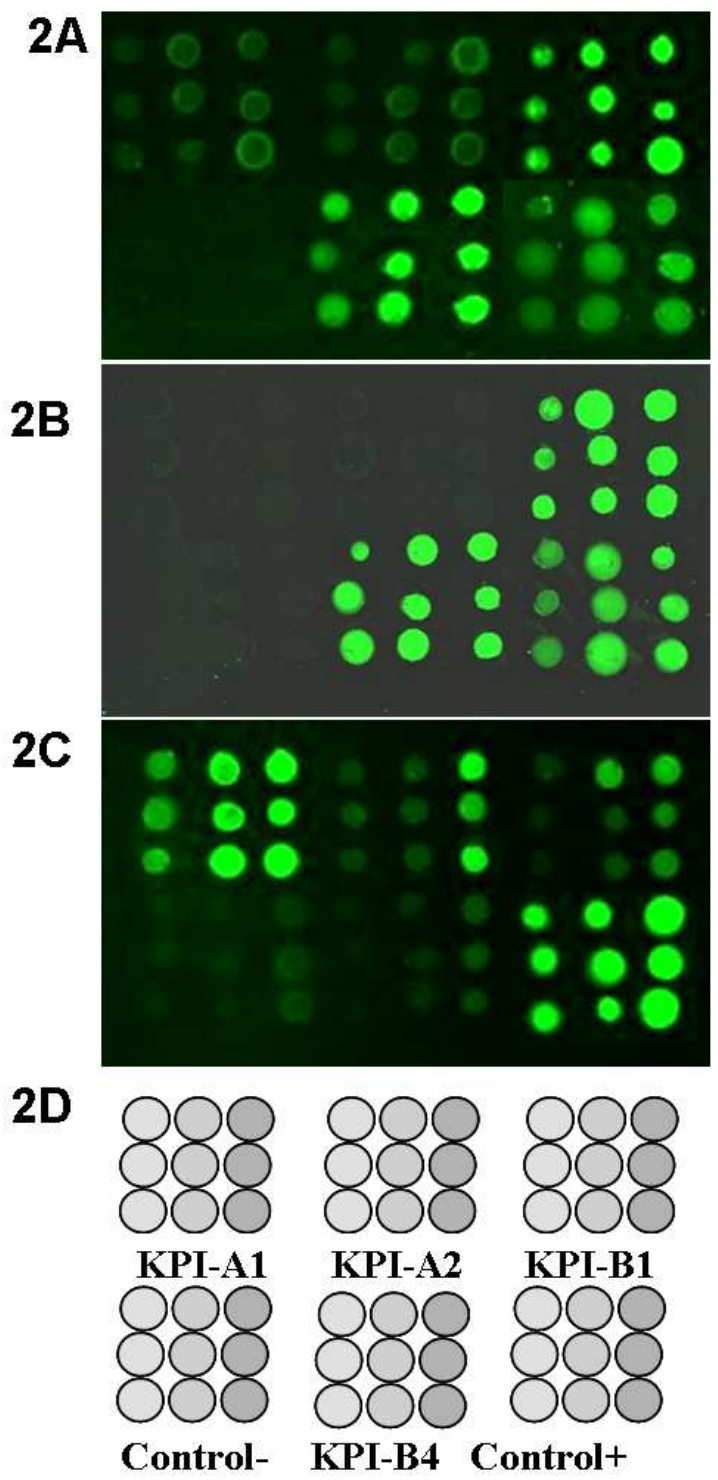

$86 \times 179 \mathrm{~mm}(150 \times 150 \mathrm{DPI})$

Wiley-VCH 


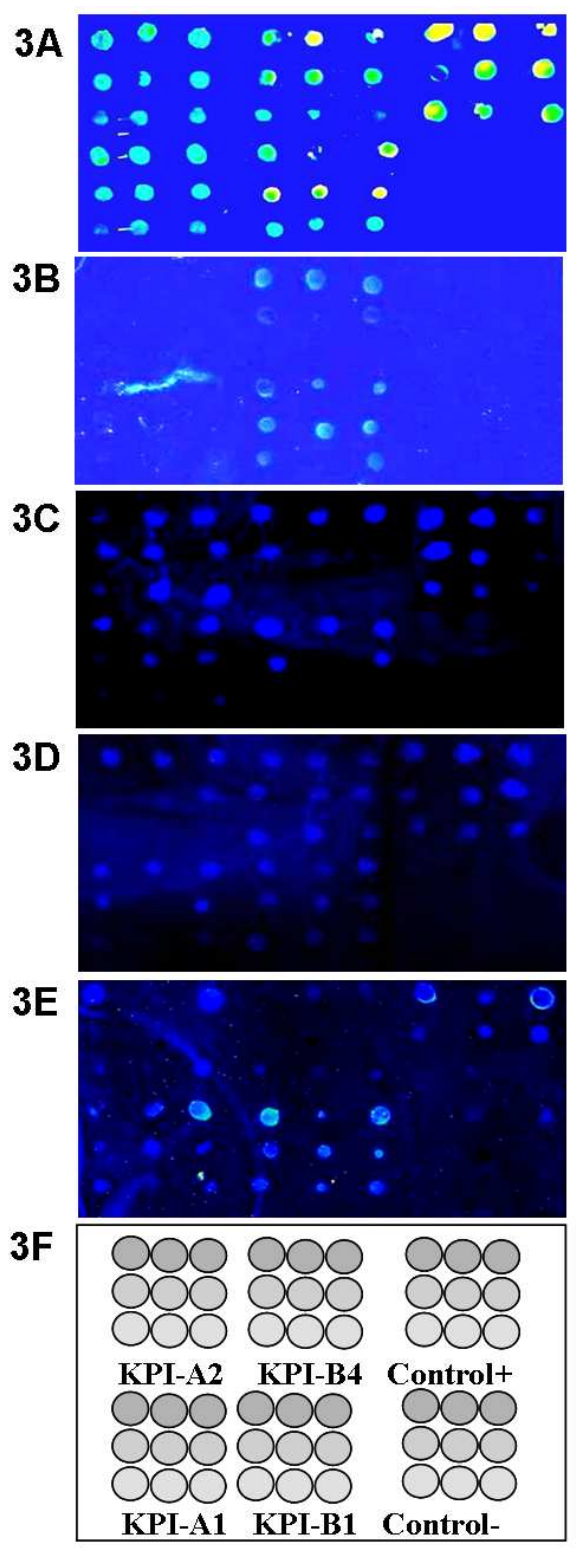

$90 \times 224 \mathrm{~mm}(150 \times 150 \mathrm{DPI})$ 